\title{
TRANSFERÊNCIA DE TECNOLOGIA PARA CULTIVARES DE TRIGO NO ESTADO DO PARANÁ ${ }^{1}$
}

\author{
LUÍS CÉSAR VIEIRA TAVARES ${ }^{2}$, MANOEL CARLOS BASSOI ${ }^{3}$, LUIZ CARLOS MIRANDA ${ }^{4}$, \\ CÁSSIO EGIDIO CAVENAGHI PRETE ${ }^{5}$
}

\begin{abstract}
RESUMO - O objetivo deste trabalho foi descrever e analisar o processo de transferência de tecnologia para cultivares de trigo desenvolvidas pela Embrapa Soja e Embrapa Transferência de Tecnologia, em parceria com produtores de sementes da Fundação Meridional. Foi utilizada metodologia sistêmica, que se caracteriza pelas fases de planejamento, instalação e condução das unidades demonstrativas, acompanhamento, realização de dias de campo, avaliação e divulgação. Esse trabalho conjunto do programa de melhoramento genético de trigo da Embrapa Soja com as empresas produtoras de sementes resultou no aumento na participação das cultivares da Embrapa no mercado de sementes, no estado do Paraná. Pelos resultados foi possível verificar a importância da transferência de tecnologia estar associada com o projeto de melhoramento, para promover e agilizar informações científicas e tecnológicas à assistência técnica pública e privada, produtores rurais e demais clientes da Embrapa.
\end{abstract}

Termos para indexação: Triticum aestivum, transferência de tecnologia, melhoramento de plantas, produção de sementes.

\section{TECHNOLOGY TRANSFER OF WHEAT CULTIVARS IN PARANÁ STATE, BRAZIL.}

\begin{abstract}
The objective of this study was to describe and analyze the technology transfer process of wheat cultivars developed by Embrapa Soybean and Embrapa Technology Transfer, in partnership with private seed producers of the Meridional Foundation. Systemic methodology, characterized by the stages of planning, establishment and management of demonstration units, establishment and monitoring of field days and evaluation and reporting of the results, was used. The work of the wheat breeding program of Embrapa Soybean with seed producers resulted in an increase in the participation of Embrapa cultivars in Paraná state's seed production. These results demonstrated the importance of associating technology transfer with wheat improvement in order to promote and speed up scientific and technological information to technical assistance, farmers and other Embrapa customers .
\end{abstract}

Index terms: Triticum aestivum, transfer of technology, plant breeding, seed production.

${ }^{1}$ Submetido em 26/01/2010. Aceito para publicação em 19/08/2010.

${ }^{2}$ Eng.Agr., M.Sc. em Melhoramento, pesquisador da Embrapa Soja, Caixa Postal 231, 86001-970, Londrina, PR ,tavares@cnpso.embrapa.br.

${ }^{3}$ Eng.Agr., Ph.D. Pesquisador da Embrapa Soja, Caixa Postal 231, 86001970, Londrina, PR, bassoi@cnpso.embrapa.br.
${ }^{4}$ Eng. Agr., Doutor em Tecnologia de Sementes . Pesquisador da Embrapa Transferência de Tecnologia , Caixa Postal 231, 86001-970, Londrina, PR,miranda@cnpso.embrapa.br

${ }^{5}$ Eng.Agr., Doutor em Fitotecnia , Professor da Universidade Estadual de Londrina, Caixa Postal 6001, CEP: 86051-990, Londrina-PR, E-mail: cássio@uel.br 


\section{INTRODUÇÃO}

O melhoramento de trigo começou no Brasil em 1919 com o estabelecimento, pelo Ministério da Agricultura, das duas primeiras estações experimentais destinadas à criação de cultivares: a Estação Experimental de Alfredo Chaves, no RS, no município de Veranópolis, e a Estação Experimental de Ponta Grossa no PR (Lagos, 1983). No Instituto Agronômico do Paraná (IAPAR) os trabalhos com melhoramento de trigo foram iniciados em 1973 e no Centro Nacional de Pesquisa de Trigo (CNPT), em Passo Fundo (RS), em 1974. Em 1974, a OCEPAR (Organização das Cooperativas do Estado do Paraná) criou o seu Programa de Pesquisa e iniciou o trabalho de melhoramento genético em trigo (Lagos, 1983). A partir de 1990, o Centro Nacional de Pesquisa de Soja também iniciou atividades de pesquisa com trigo, no distrito de Warta, envolvendo testes de genótipos criados pelo CNPT (Sousa, 2000). No ano de 1992 foi iniciado um programa de melhoramento genético específico para o Paraná, com apoio da ABITRIGO- Associação Brasileira da Industria de Trigo (Dotto e Bassoi, 1994).

A adaptação do trigo para as condições de clima e solo do Paraná foi iniciada no início dos anos 70 e consolidada por um esforço contínuo de diversas instituições de pesquisa, como IAPAR, COODETEC e Embrapa, utilizando o melhoramento genético e desenvolvendo técnicas eficientes de manejo da cultura (Brunetta e Dotto, 2000). O programa de melhoramento genético na Embrapa Soja, em parceria com a Embrapa Trigo teve seu início em 1992 com a finalidade de suprir o Paraná com cultivares que apresentassem características para atender necessidades do produtor e da indústria, tais como: tolerância ao alumínio tóxico, resistência às doenças, potencial e estabilidade no rendimento de grãos, qualidade industrial e ampla adaptação. Essas características vêm sendo incorporadas e predominam como objetivo do melhoramento.

Os trigos chamados de "antigos" tinham a rusticidade (adaptação e resistência geral aos estresses bióticos e abióticos) como sua característica de destaque. Por outro lado, as cultivares de trigo, chamadas "modernas", têm porte baixo, apresentando grande redução na incidência de acamamento, e potencial mais elevado de rendimento de grãos. A adição de novos genes de resistência às doenças, pragas e aos estresses abióticos têm proporcionado significativo aumento no potencial de rendimento de grãos, que hoje facilmente ultrapassa os $1.500 \mathrm{~kg} \cdot \mathrm{ha}^{-1}$ alcançados nas boas lavouras de 20 anos atrás, e até ultrapassando os $5.000 \mathrm{~kg} \cdot \mathrm{ha}^{-1}$ em muitas lavouras do sul e centro-sul do
Brasil, sob ambiente de chuva normal (Scheeren et al., 2002). Resultado importante obtido pelos melhoristas brasileiros foi a introdução da cultivar IAS 54, contendo o gene Rht. Em estudos comparando o rendimento de grãos entre as cultivares lançadas no período de 1940 a 1992, no Rio Grande Sul, observou-se que o rendimento de grãos das cultivares modernas foi significativamente superior às antigas, sendo esse ganho genético de 1,54\% ano (Rodrigues et. al., 2002).

Para demonstrar o avanço do melhoramento genético, estudos realizados por Nedel (1994) para calcular o ganho genético do trigo entre 1940 e 1992, demonstraram um incremento médio de $17,3 \mathrm{~kg} \cdot \mathrm{ha}^{-1} / \mathrm{ano}$. No Paraná, Tavares (1998) observou ganhos genéticos do trigo em 12 anos agrícolas, no período de 1985 a 1996, de 71,87 kg.ha-1/ano, em Londrina; 36,90 kg.ha-1/ano, em Palotina; 112,22 kg.ha-1/ ano, em Cascavel e 82,37 kg.ha-1/ano, em Ponta Grossa. Os avanços genéticos obtidos no Paraná demonstram o desenvolvimento contínuo de genótipos adaptados às condições de ambiente, comprovando que os programas de melhoramento de trigo foram eficientes. Até 1997, as empresas de melhoramento desenvolviam as atividades de avaliação e recomendação de novas cultivares de forma cooperativa, cumprindo a portaria ministerial $\mathrm{n}^{\circ} 178$ de 21 de julho de 1981 (Brasil, 1981) que instituiu o Sistema Brasileiro de Avaliação e Recomendação de Cultivares. A partir de 1998, com a aprovação da Lei de Proteção de Cultivares, que instituiu o Registro Nacional de Cultivares e condicionou a inscrição da cultivar à previa realização de ensaios para determinação de VCU-Valor de Cultivo e Uso, sob a responsabilidade exclusiva do obtentor da cultivar, cada empresa ficou responsável pelos seus experimentos e lançamentos (Brasil, 2002).

Até o final da década de 70, as informações sobre cultivares de trigo faziam parte de pacotes tecnológicos elaborados por pesquisadores e agentes da assistência técnica. Esses pacotes tornavam-se normas nas instituições de crédito rural para as operações de financiamento das lavouras de trigo. Nesse período, praticamente, nenhuma atividade específica de transferência de cultivares foi desenvolvida pela pesquisa, pela assistência técnica ou por empresas de sementes. Essa situação se manteve até meados da década de 1980, quando foram iniciadas ações específicas (palestras, dias de campo, publicações) para a transferência de informações sobre as cultivares em fase de recomendação, para o Paraná (Domit et al.,2007). Entretanto, essas atividades eram pontuais, sem fazer parte de um projeto sistêmico que envolvesse todos os componentes da cadeia produtiva de sementes de 
trigo. A Embrapa Soja começou a desenvolver um projeto de transferência de tecnologia, utilizando metodologia sistêmica, para as cultivares de trigo e recomendações técnicas para o seu manejo, a partir da safra 1999. E na Embrapa a transferência de tecnologia como política empresarial iniciou a partir do momento em que, além de oferecer bons produtos e serviços, a empresa passou a montar, em parceria com setores públicos e privados, sistemas de distribuição e de promoção para ter sucesso na transmissão das tecnologias geradas (Embrapa, 1998). Essa evolução no processo de transferência de tecnologia teve como objetivo operacionalizar e disponibilizar soluções para o atendimento às demandas da sociedade, através de produtos e serviços que possam ser viabilizados pela Embrapa e por seus parceiros, mediante planejamento, execução, acompanhamento e avaliação integrada de planos de marketing e transferência de tecnologia, realizados pelas unidades da empresa ou em parceria com instituições públicas e privadas (Embrapa, 2004). Com isso, ocorreu maior profissionalização em todo o processo de transferência de tecnologia relacionado com cultivares de trigo.

Os objetivos deste trabalho foram descrever a parceria público privada da Embrapa Soja, Embrapa Transferência de Tecnologia com a Fundação Meridional; demonstrar a melhoria na participação do mercado de sementes; descrever e analisar o processo de transferência de tecnologia para cultivares de trigo, desenvolvidas pela Embrapa Soja e Embrapa Transferência de Tecnologia, em parceria com produtores de sementes do Paraná e ampliar a discussão na pesquisa sobre a importância da transferência de tecnologia para o desenvolvimento de novas cultivares.

\section{MATERIAL E MÉTODOS}

Em 1999 com a criação da Fundação Meridional de Apoio à Pesquisa Agropecuária e participação da Embrapa Soja, Embrapa Transferência de Tecnologia em parceria com 61 empresas de sementes dos estados Paraná, São Paulo e Santa Catarina. A fundação viabilizou a sustentação técnica e financeira aos programas de melhoramento genético das culturas de soja e trigo, além de desenvolver trabalhos de transferência de tecnologia através da realização de vitrines de tecnologias, unidades demonstrativas, dias de campo, palestras em conjunto com Embrapa e IAPAR. São oportunidades de mostrar as melhores tecnologias de produção do trigo desde a escolha da cultivar e da semente, manejo da cultura, monitoramento e manejo de pragas, doenças e plantas daninhas. Dentre os resultados gerados pela parceria Embrapa Soja, Embrapa de Transferência de Tecnologia, Embrapa Trigo e Fundação Meridional até 2009 lançaram 10 cultivares de trigo: BRS 193, BRS 208, BRS 209, BRS 210, BRS 220, BRS 229, BRS 248, BRS 249, BRS Pardela, BRS Tangará. Isso mostra que através da Transferência de tecnologia há interação entre a Embrapa e seus parceiros, clientes e usuários de tecnologias produzidas e adoção dos produtos, processos e serviços.

Neste trabalho utilizaram-se dados da produção de sementes de trigo no estado do Paraná - SEAB/ DERAL,ABRASEM, Fundação Meridional no período de 1993/1994 a 2007/2008, nos resultados do Projeto de "Transferência de Tecnologia para as Cultivares de Trigo Desenvolvidas pela Embrapa Soja para o Paraná”, iniciado em 1999, na qual a Embrapa Soja, Embrapa Transferência de Tecnologia, IAPAR e Fundação Meridional são os gestores. Este projeto está estruturado da seguinte forma:

\section{1) Características}

1.1) Parceria coma Embrapa Transferência de Tecnologia e com empresas produtoras de sementes, selecionadas segundo critérios técnicos e que essas fossem portadoras de cadastro idôneo junto aos órgãos de fiscalização, com disposição para investir no projeto de transferência;

\section{2) Estratégia de ação}

2.1) Métodos de transferência:

2.1.1) Dia de Campo (DC) - demonstrações práticas de resultados de pesquisa e transferência de tecnologia, conhecimentos, inovações e imagens, por meio de visitas aos campos experimentais, áreas demonstrativas ou dia de campo na TV;

2.1.2) Reunião Técnica (RT) - reuniões organizadas sob responsabilidade da Embrapa Soja e parceiros, com o objetivo de planejar as atividades e avaliar os resultados alcançados;

2.1.3) Visitas Técnicas (VT) - acompanhamento dos trabalhos de campo;

2.1.4) Unidades de Demonstração (UD) - demonstração de resultados de tecnologias geradas pela Embrapa na forma de produto final, instalada sob a supervisão da Embrapa Soja e parceiros, geralmente com a coparticipação de órgãos de assistência técnica privada e/ou oficial.

\section{2) Metodologia sistêmica}

Caracterizada pelas fases de planejamento, instalação acompanhamento, e condução das UD, realização de dias de campo e avaliação e divulgação. Essa metodologia teve a participação efetiva da coordenação do projeto, de pesquisadores envolvidos no programa de melhoramento e representantes das empresas produtoras de sementes 
selecionadas. Conforme Figura 1, no esquema funcional e operacional do projeto transferência de tecnologia, a validação e transferência de tecnologias estão integradas. $\mathrm{O}$ método é compreendido pelas seguintes fases:

- Planejamento: antes de cada safra, a Embrapa Soja reuniu todos os parceiros do projeto, para discutir a execução e definir as ações que seriam desenvolvidas; Instalação e condução da UD: responsabilidade de técnicos da Embrapa Soja, parceiros e/ou técnico responsável pela UD, conforme o definido no projeto. Cada UD foi instalada e conduzida seguindo as indicações técnicas da pesquisa;

- Visita de acompanhamento técnico - pesquisadores e técnicos envolvidos no programa de desenvolvimento de cultivares de trigo realizaram visitas às UDs, com o objetivo de avaliar as unidades e planejar os dias de campo;

- Dia de campo - evento organizado pela Embrapa e/ ou parceiros nas UDs e com a participação de técnicos e produtores rurais. A Embrapa forneceu suporte técnico através de seus pesquisadores, para proferir palestras e atender consultas sobre temas definidos e;

- Avaliação e divulgação - depois de cada safra, os responsáveis técnicos pelas UDs se reuniram na Embrapa Soja em Londrina, para apresentação e discussão dos resultados obtidos nessas unidades, inclusive do levantamento de informações sobre a aceitação das novas cultivares pelos agricultores e técnicos.

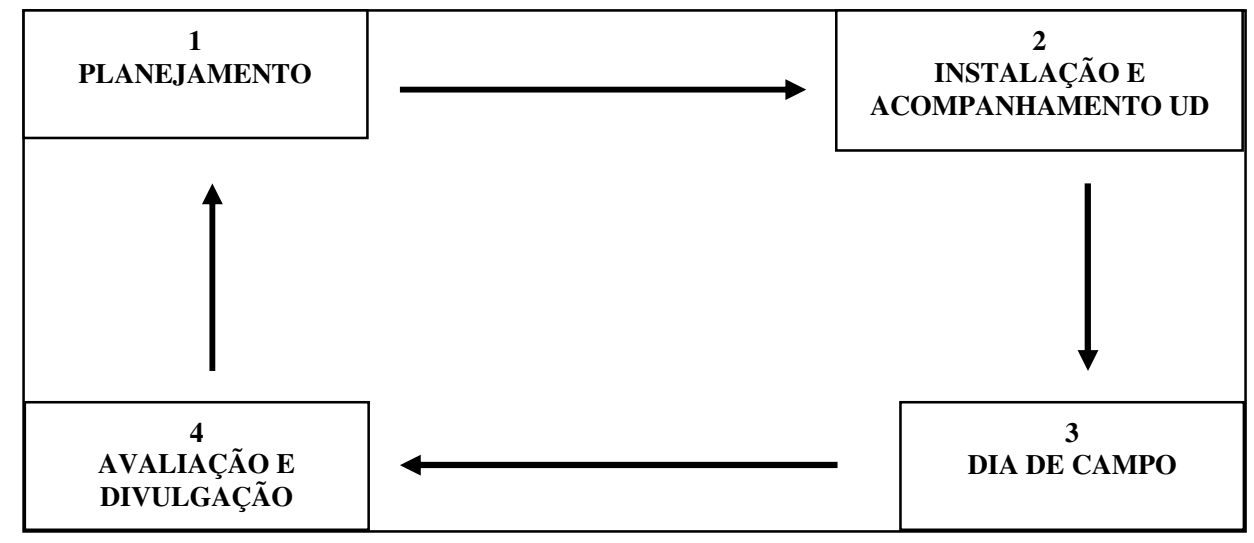

FIGURA 1. Esquema funcional do projeto transferência de tecnologia e participação da parceria pública privada Embrapa/Fundação Meridional.

\section{RESULTADOS E DISCUSSÃO}

O projeto de transferência de tecnologia incluiu novas atividades, que tinham o objetivo de aprimorar o processo de transferência de cultivares e recomendações para o seu manejo e de marketing institucional de todos os participantes do projeto, através de palestras sobre marketing e mercado de sementes, ampliação dos conhecimentos e tecnologias nas unidades demonstrativas e ampliação do marketing institucional e técnico. Na Figura 2 está descrito o modelo de parceria público-privada, onde a Fundação Meridional pode ser considerada o elo de ligação entre os produtores de sementes facilitando dessa forma a parceria e condução de trabalhos em conjunto.

Na Figura 3 é mostrada a produção de sementes de trigo da safra 94/95, com 118.000 t, até uma evolução da produção na safra 2007, com 160.000 t. Pode-se observar que para a produção de trigo houve um crescimento a partir da safra 97/98, justamente quando a Lei de Proteção de Cultivares passou a vigorar. Houve diminuição na produção de sementes em 2001, em função de geada no ano anterior. A maior concorrência e a maior exigência do mercado comprador levou a uma maior profissionalização e eficiência das empresas produtoras de sementes e aquelas que não se adequaram a essa realidade encerraram suas atividades. A utilização de sementes de trigo sempre ficou com taxas acima de $80 \%$, mas observou-se uma diminuição nos últimas safras devido a sementes clandestinas, conforme a figura 4. Nas Figuras 5 e 6 são mostradas parte das atividades desenvolvidas no projeto de transferência com a entrada da Fundação Meridional. Na safra 2001 foram realizados 25 dias de campo com a participação de 5.500 participantes entre técnicos e produtores, evoluindo nas safras seguintes para 40 dias de campo e com 8.500 participantes.

As ações do projeto de transferência, aliado ao lançamento de novas cultivares pela Embrapa, pode ter 
atendido os interesses dos produtores de trigo do Paraná, visto que resultou num rápido aumento na participação das cultivares da Embrapa Soja, a partir de 2.003 (Figura 7). Antes da parceria, o programa de melhoramento genético de trigo da Embrapa situava-se apenas em Passo Fundo, em condições edafoclimáticas nem sempre similares às condições do Paraná, principalmente nas regiões Norte e Oeste. Com o melhoramento genético sendo também realizado na Embrapa Soja, em Londrina, e com uma ampla rede de testes proporcionada pela parceria, foi possível o lançamento de cultivares mais estáveis e adaptadas às condições do Paraná. A Figura 7 mostra que, a partir da parceria, as cultivares da Embrapa tiveram um aumento de participação no mercado de maneira gradativa e sustentável. Essa participação aumentou de $15 \%$, em 2003, para 47,5\% em 2009.

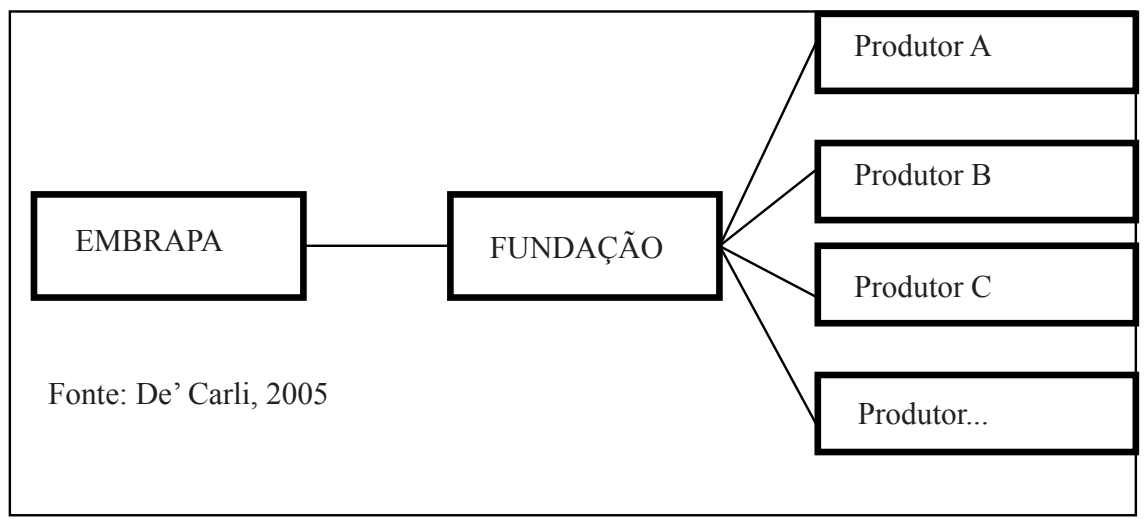

FIGURA 2. Modelo de Parceria Público-Privada encontrado na Embrapa.

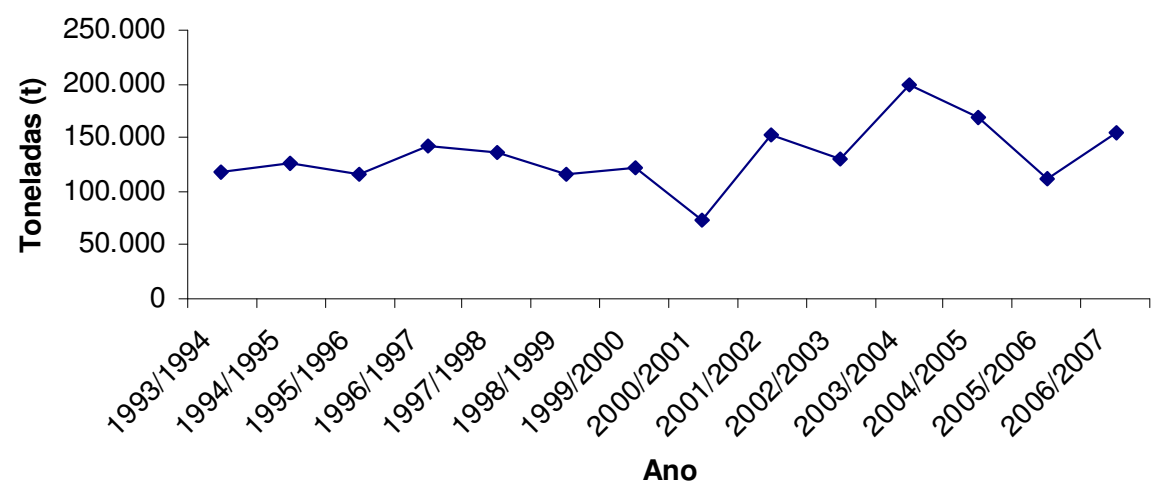

FIGURA 3. Produção de sementes de trigo (t) da safra 94/95 ate a safra 2007, no estado do Paraná.

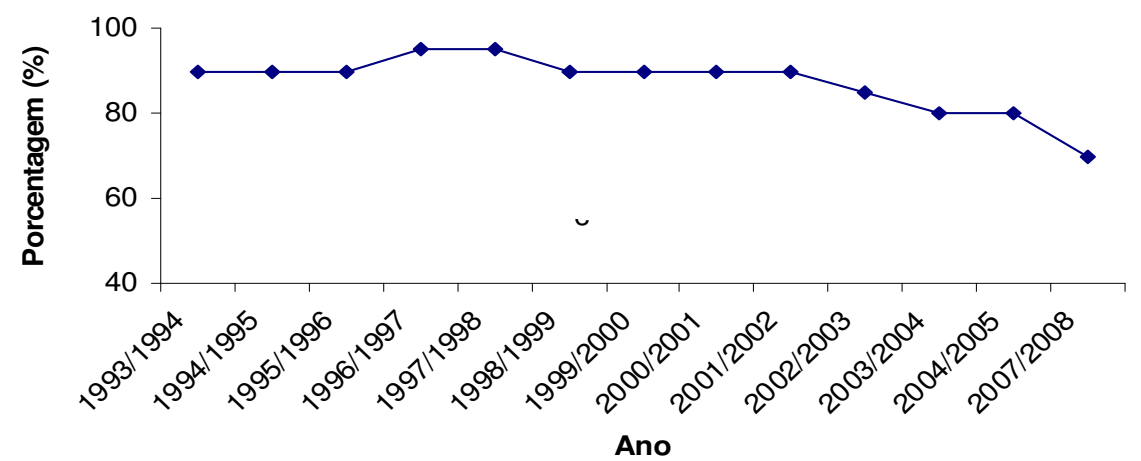

FIGURA 4. Porcentagem de utilização de sementes de trigo no Brasil. 


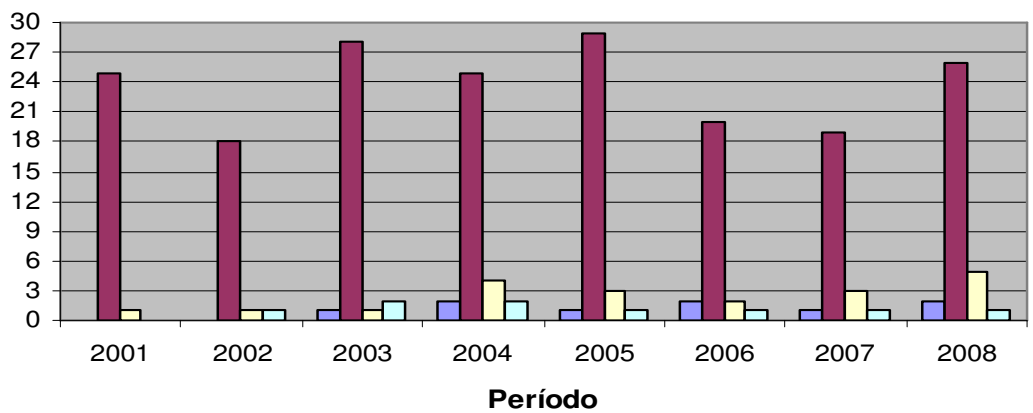

$\square$ MT Eventos $\square$ PR Eventos $\square$ SC Eventos $\square$ SP Eventos

FIGURA 5. Dias de campo no PR, SP, SC e MS realizadas pelos colaboradores da Embrapa, Fundação Meridional e IAPAR.

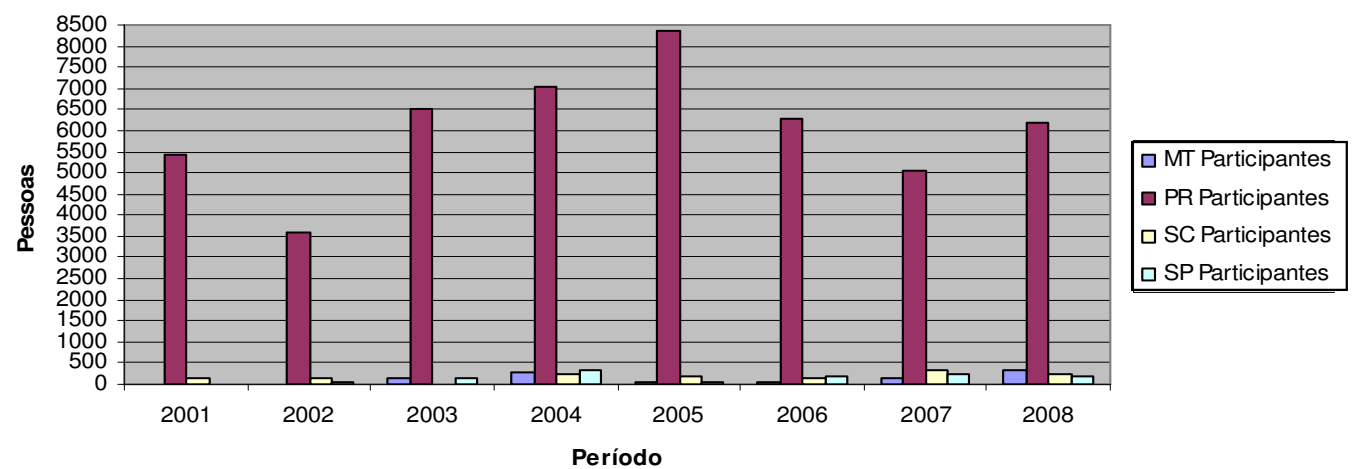

FIGURA 6. Número de participantes nos dias de campo realizados pelos colaboradores da Embrapa, Fundação Meridional e IAPAR.

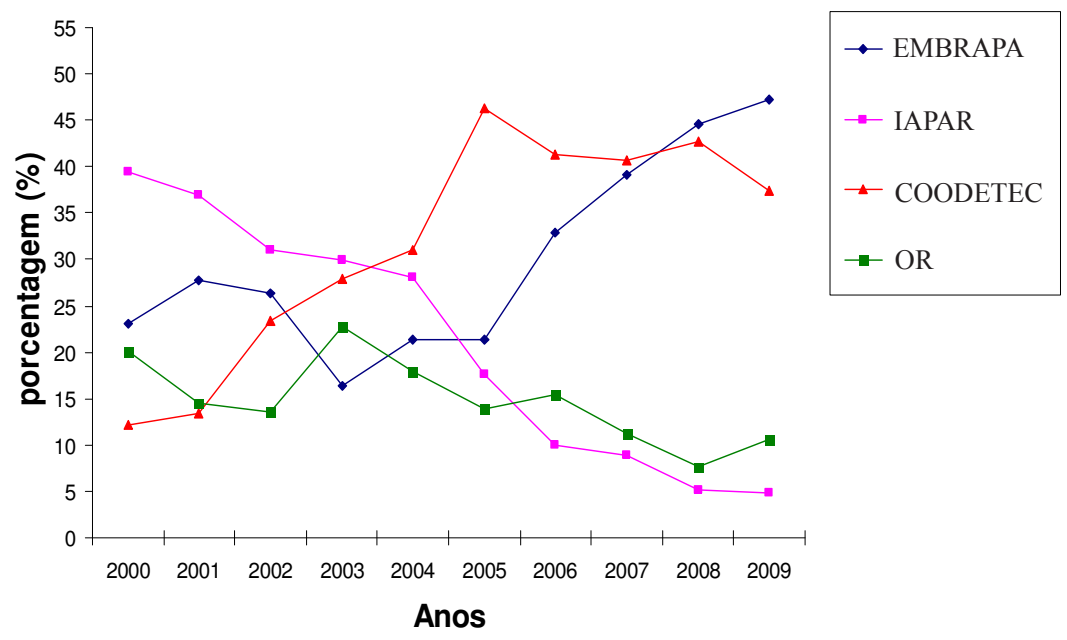

Fonte: Fundação Meridional, 2009.

FIGURA 7. Percentagem de participação das empresas no mercado de sementes de trigo. 


\section{CONCLUSÕES}

O projeto de transferência de tecnologia para as cultivares de trigo é fundamental para que as cultivares da Embrapa aumentassem sua participação no mercado de sementes no estado do Paraná.

O projeto de transferência de tecnologia deve estar associado com o projeto de melhoramento genético de trigo, na rápida disseminação de informações cientificas e tecnológicas, além das ações integradas entre pesquisador, extensão rural e produtores.

\section{AGRADECIMENTOS}

ÀEmbrapa Soja,Embrapa Transferência de Tecnologia, pelo apoio.

À Fundação Meridional, SEAB, que forneceram dos dados para produção de sementes de trigo para o estado do Paraná.

Ao papel importante do projeto de transferência de Tecnologia das cultivares de trigo desenvolvidas pela Embrapa Soja para o Paraná.

\section{REFERÊNCIAS}

BRASIL. Portaria n. 178, de 21 de julho de 1981. Diário Oficial da União, Brasília, DF, 22 de julho de 1981. Seção I, p.13764.

BRASIL. Serviço Nacional de Proteção de Cultivares. Ministério da Agricultura, Pecuária e Abastecimento. Catálogo de cultivares protegidas de trigo: Triticum aestivum L. Brasília, DF: APA/SARC/SNPC/LADIC, 2002. 130p.

BRUNETTA, D.; DOTTO, S.R. Trigo no Paraná: visão histórica, situação atual e perspectivas. In: CUNHA, G.R., (Org.). Trigo no Brasil: rumo ao século XXI. Passo Fundo: Embrapa Trigo, 2000.p.129-135.

DE CARLI, C.R. Embrapa: precursora da Parceria Público-Privada no Brasil, (UnB-CDS, Mestre, Política e Gestão de C\&T, 2005). 155f. Dissertação de MestradoUniversidade de Brasília. Centro de Desenvolvimento Sustentável, 2005.

DOMIT, L.A. visão sobre transferência de tecnologia na Embrapa. In: OLIVEIRA, M.C.B.; LIMA, D. de. Manual de implantação do treino e visita $(T \& V)$. Londrina: EMBRAPA Soja, 2007. p.14-20. (EMBRAPA Soja. Documentos, 288).
DOTTO, S.R.; BASSOI.; M.C. Resultados de pesquisa com trigo no CNPSo - safra 1992. Londrina: EMBRAPACNPSo, 1994. 104p. (EMBRAPA-CNPSo. Documentos, 73).

EMBRAPA. Política de negócios tecnológicos. Brasília, DF: Embrapa-SPI, 1998, 44p.

EMBRAPA. IV Plano Diretor da Embrapa: 2004-2007. Embrapa. Secretária de Administração e EstratégiaBrasília, DF. 2004. 48p.

LAGOS, M.B. História do melhoramento do trigo no Brasil. Porto Alegre: IPAGRO, 1983. 80p. (IPAGRO. Boletim Técnico, 10).

NEDEL, J.L. Progresso genético no rendimento de grãos de cultivares de trigo lançadas para cultivo entre 1940 e 1992. Pesquisa Agropecuária Brasileira, v.29, p.15651570, 1994.

RODRIGUES, O.; DIDONET, A.D.; LHAMBY, J.C.B.; TEIXEIRA, M.C.C.; DEL DUCA.; L. de J. Características fisiológicas associadas ao avanço no potencial de rendimento de grãos de trigo. Passo Fundo: Embrapa Trigo, 2002. 26p. (Embrapa Trigo. Boletim de Pesquisa e Desenvolvimento Online, 6). Disponível em: $<$ http://www. cnpt.embrapa.br/biblio/p_bp06.htm>. Acesso em: 22 ago. 2010.

SCHEEREN, P.L.; CUNHA, G.R. da; SÓ E SILVA, M.; SOUSA, C.N.A. de.; DEL DUCA, L. de J.A.; CAETANO, V. da R.; BRUNETTA, D.; DOTTO, S.R.; BASSOI, M.C.; SOUSA, P.G. de; ALBRECHT, J.C.; ANDRADE, J.M.V. de; CÁNOVAS, A.; SOARES SOBRINHO, J.O Melhoramento e os trigos da Embrapa em cultivo no Brasil. Passo Fundo: Embrapa Trigo, 2002. 5p. Publicação Online. (Embrapa Trigo. Comunicado Técnico, 81).

SECRETARIA DE ESTADO DA AGRICULTURA E ABASTECIMENTO/PR. Dados estatísticos de produção de sementes classes: registrada, certificada, fiscalizada. Curitiba: SEAB-PR/Departamento de Fiscalização: Coordenadoria da Produção de Sementes e Mudas. Documentos entre 2001 e 2008.

SOUSA, C.N.A. de.; DEL DUCA, L. de J.A. Cultivares de trigo no Brasil: III - cultivares desenvolvidas pela Secretaria da Agricultura do Rio Grande do Sul após 1950. Passo Fundo: Embrapa Trigo, 2000. 64p. (Embrapa Trigo. Documentos, 18).

TAVARES, L.C.V. Avaliação do progresso genético do trigo (Triticum aestivum L.) no estado do Paraná. 1998. 79f. Dissertação (Mestrado) - Faculdade de Ciências Agrárias e Veterinárias - Campus de Jaboticabal Universidade Estadual Paulista, Jaboticabal, 1998. 